\title{
Identification of new cell size control genes in S. cerevisiae
}

\author{
Huzefa Dungrawala', Hui Hua', Jill Wright', Lesley Abraham,2, Thivakorn Kasemsri, Anthony McDowell', \\ Jessica Stilwell ${ }^{1,2}$ and Brandt L Schneider ${ }^{1 *}$
}

\begin{abstract}
Cell size homeostasis is a conserved attribute in many eukaryotic species involving a tight regulation between the processes of growth and proliferation. In budding yeast S. cerevisiae, growth to a "critical cell size" must be achieved before a cell can progress past START and commit to cell division. Numerous studies have shown that progression past START is actively regulated by cell size control genes, many of which have implications in cell cycle control and cancer. Two initial screens identified genes that strongly modulate cell size in yeast. Since a second generation yeast gene knockout collection has been generated, we screened an additional 779 yeast knockouts containing 435 new ORFs ( $\sim 7 \%$ of the yeast genome) to supplement previous cell size screens. Upon completion, 10 new strong size mutants were identified: nine in log-phase cells and one in saturation-phase cells, and $97 \%$ of the yeast genome has now been screened for cell size mutations. The majority of the logarithmic phase size mutants have functions associated with translation further implicating the central role of growth control in the cell division process. Genetic analyses suggest ECM9 is directly associated with the START transition. Further, the small (whi) mutants mrp/49 $\Delta$ and cbs $1 \Delta$ are dependent on CLN3 for cell size effects. In depth analyses of new size mutants may facilitate a better understanding of the processes that govern cell size homeostasis.
\end{abstract}

Keywords: Yeast, Cell cycle, Cell size, Growth, Cyclins

\section{Introduction}

Cell size homeostasis is physiologically important to nearly all organisms. This is evident from the uniformity and conservation of size within a cell lineage amongst the individuals of a species from bacteria to man [1]. Moreover, studies in flies, mice and humans indicate the presence of an organ size checkpoint during developmental stages [2]. To ensure a population of cells that maintain a constant average cell size, it is essential that cells coordinate the processes of growth, which increases cell size, and cell division, which reduces cell size [3]. Irregularities in these processes affect fitness and function [4]. In the budding yeast S. cerevisiae, coordination of growth and division occurs at START, the point of commitment to the cell cycle $[5,6]$ which is equivalent to the Restriction point in mammalian cells [7]. At START, a cell transits, essentially irreversibly, from G1- to S-phase. Early

\footnotetext{
* Correspondence: brandt.schneider@ttuhsc.edu

${ }^{1}$ Department of Cell Biology and Biochemistry, Texas Tech University Health

Sciences Center, 3601 4th St Rm. 5C119, Lubbock, TX 79430, USA

Full list of author information is available at the end of the article
}

genetic analyses of START revealed that blocking cell growth prevents cell cycle progression [5]. However, the converse is not true [5]. For example, the discovery of cell division cycle $(C D C)$ genes, a class of essential genes involved in cell cycle control, established that cell growth is a continuous process that proceeds unabated even when cell cycle progression is halted [8]. The end result is the production of abnormally large cells [5]. Thus, the mechanisms that regulate the cell cycle can have a profound impact on cell growth and vice versa.

Physiological studies in yeast and mammalian cells suggest that cells undergo exponential growth throughout the cell cycle [4,9-12]. Since exponential growth is inherently tied to cell size (e.g. larger cells grow faster than smaller cells), some type of "size sensing" mechanism is required for cell size homeostasis $[4,13,14]$. While the mechanism remains somewhat obscure, evidence suggests that in yeast commitment to division is linked to cell size $[4,13,14]$. In yeast, cells must attain a certain "critical cell size" before commitment across START [5,15], but while there are hints of a "size sensing"

\section{Biomed Central}


mechanism in mammalian cells, it is less clear if a similar "critical cell size" phenomenon exists in mammalian cells [9,16-20]. Nonetheless, the investigation of cell size mutants has provided mechanistic clues to START regulation in yeast. For example, some of the very first cell size mutants in yeast implicated cyclins and cyclin dependent kinases (Cdks) in the control of cell size [21-23]. These included mutants that stabilized cyclins (e.g. CLN3-1) in budding yeast or promoted the activity of Cdks in fission yeast (e.g. wee1) [22-25]. Subsequently, genome-wide genetic screens systematically identified yeast mutants with altered cell size phenotypes [26,27]. These studies led to the identification of genes which play a strong role in regulating cell cycle progression past START [26,27]. Mutants which alter CLN expression strongly alter cell size phenotypes. For example, deletion of the START inhibitor WHI5 results in a population of cells with a small size phenotype [26,27]. Conversely, deletion of $C L N 3$ or $B C K 2$, upstream activators of $C L N$ expression cause a cell cycle delay thus inducing a large cell size phenotype $[28,29]$. Deleting both CLN3 and BCK2 results in inviability, but $\ln 3 \Delta b c k 2 \Delta$ cells can be partially rescued by inducing CLN2 expression ectopically or by deleting WHI5 [29-32]. Deletion of the transcription factors that regulate CLN transcription (e.g. SWI4 and SWI6) also results in a large cell size phenotype [33]. In contrast, early CLN expression advances cell cycle progression and reduces cell size $[31,32]$. Thus, many genes involved in cell size control appear to interface with the mechanisms that regulate progression past START in budding yeast [26].

Cell size is sensitive to the conditions of external environment. Size homeostasis mechanisms exist during nutritional up shift, that are distinctly different from those involved in steady-state environment conditions [34]. Cells cultured in poor nutrients grow slower and are smaller compared to isogenic populations cultured in rich environmental conditions [35-38]. As such, ribosome biogenesis has been strongly implicated in modulating critical cell size for yeast cells at START $[37,39,40]$. Furthermore, genes implicated in the process of ribosome biogenesis are also size mutants [26,27]. Indeed, a recent report has established multiple genes that function in protein synthesis as strong regulators of START [39]. Interestingly, the majority of mutants that altered cell cycle progression did not affect cell size and vice versa [39]. Despite these observations, evidence suggests that carbon source modulates size via Clns [41,42], and that growth rates are potentially linked to $C L N$ thresholds for START entry $[38,43,44]$. These results warrant further investigation into the mechanistic regulation of cell division by genes affecting growth and cell size which would help elucidate the relationship between nutrient transduction signals and cell cycle entry. Also, nutrient sensing pathways play an important role in modulating the aging process in various model systems
[45]. Thus, it would be beneficial in elucidating the coordination between growth and proliferation under different nutritional environments.

The basic mechanisms of cell cycle control are well conserved evolutionarily. Not only is gene function highly conserved, but the products of these genes also appear to have the same fundamental role in the regulation of cell size from yeast to man [1]. Indeed, an analogous system for G1-S transition exists between yeast and mammals wherein $\mathrm{Cln} 3, \mathrm{SBF}$ and Whi5 play similar roles to that of cyclin D, E2F and RB respectively [46-48]. Moreover, like their yeast homologs, the expression of cyclin D, E2F and RB influences cell size homeostasis. For example, cells lacking cyclin D are larger than normal while cells over-expressing cyclin D are smaller than normal [49-53]. Moreover, like whi5 $\Delta$ strains, cells lacking $\mathrm{pRb}$ are smaller than normal [54-56]. Conversely, loss of E2F function increases cell size [57]. The extent of evolutionary conservation of cell cycle genes between yeast and mammals signifies the importance of cell size control studies in S. cerevisiae. Although the genetic pathways involved in cell cycle control are well established, the mechanisms whereby these same pathways modulate cell size are not well understood. Therefore, the elucidation of gene function in yeast is likely to provide valuable insights into mammalian cell biology.

For this study, we screened the entire yeast knock-out collection version 2 (YKOv2) containing 779 ORF deletions for cell size mutants. From this screen, 10 new strong size mutants were identified: nine from logarithmic and one from saturation cultures. Like previous screens, the majority of the size mutants are involved in some aspect of the translation process. This further implicates the control of translation in the mechanisms that coordinate growth and proliferation, and completion of this screen will provide a valuable database for researchers interested in dissecting the process of cell size control.

\section{Results}

\section{Cell size screen analysis}

In the two previous studies, 5958 diploid deletion strains were screened for cell size mutants in saturated cultures [27] while 4812 haploid deletion strains were analyzed in log-phase cultures [26]. In total, $\sim 90 \%$ of the $6607 \mathrm{cu}$ rrently annotated yeast ORFs were evaluated for cell size defects $[26,27,58]$. To expand upon these results, the second generation yeast gene deletion strain collection (YKOv2) was obtained from OPEN Biosystems. These included all the additions/updates (e.g. new ORF annotations that were added to the existing database) and corrections to the previous collection $[59,60]$. Thus, a total of 779 diploid strains were sized in both logarithmic and saturated cultures to identify new cell size mutants 
(Additional file 1: Table S1). Amongst these strains were 435 new ORF deletions (235 essentials and 200 nonessentials constituting $\sim 7 \%$ of the genome) which have not been sized previously (Additional file 1: Table S1). Consequently, after this current screen, $\sim 97 \%$ of the available yeast ORFs have now been screened for cell size mutants.

The size curves of budding yeast cultures are usually not normal distributions (Figure 1A), but rather are positively skewed to the right (Figure $1 \mathrm{~B})$. Therefore, we collected and compared average mean, median and mode size values as previously described [27]. To ensure the proper identification of the size mutants, outliers were selected as potential size mutants on the basis of being $+/-2$ standard deviations from average mean, median and mode values (see Materials and Methods). This methodology was applied to both logarithmic and saturation phase readings (Additional file 2: Figure S1). Evaluation of mean cell sizes from the entire population of logarithmic and saturated cultures revealed a distribution curve that was nearly identical to our previous study (Additional file 3: Figure S2 and data not shown).
In addition, screenings identified 10 new deletion strains as potential size mutants: 9 in logarithmic phase and 1 in saturation phase. In total in log phase, seven gene

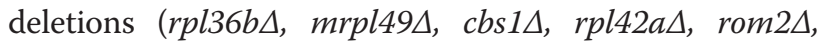

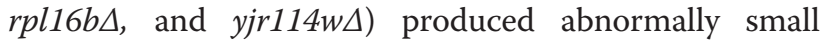
(whi) cells while two gene deletions (ctr9 4 and ecm9 4 ) increased cell size (uge mutants) in log phase (Table 1). Only one gene deletion, $\operatorname{ctr} 9 \Delta$, was found to significantly alter size in saturation and produced abnormally large cells (Table 1). Representative cell size plots for a whi mutant, rpl36b $\Delta$ and an uge mutant, ctr9 9 are shown in Figure 1C.

Internal controls within the second generation deletion collection allowed us to test the reproducibility of previous cell size measurements. For example, of the 779 deletion strains in YKOv2, 144 were newly constructed deletions of previously knocked-out genes [60]. Importantly, sizing of these new deletions led to the identification of four new size mutants ( $c b s 1 \Delta, r p l 16 b \Delta$, rom $2 \Delta$, rpl42a $\Delta$ ) suggesting that the original deletions might not have completely removed the function from these ORFs. However, 132/140 (94.2\%) of the remaining
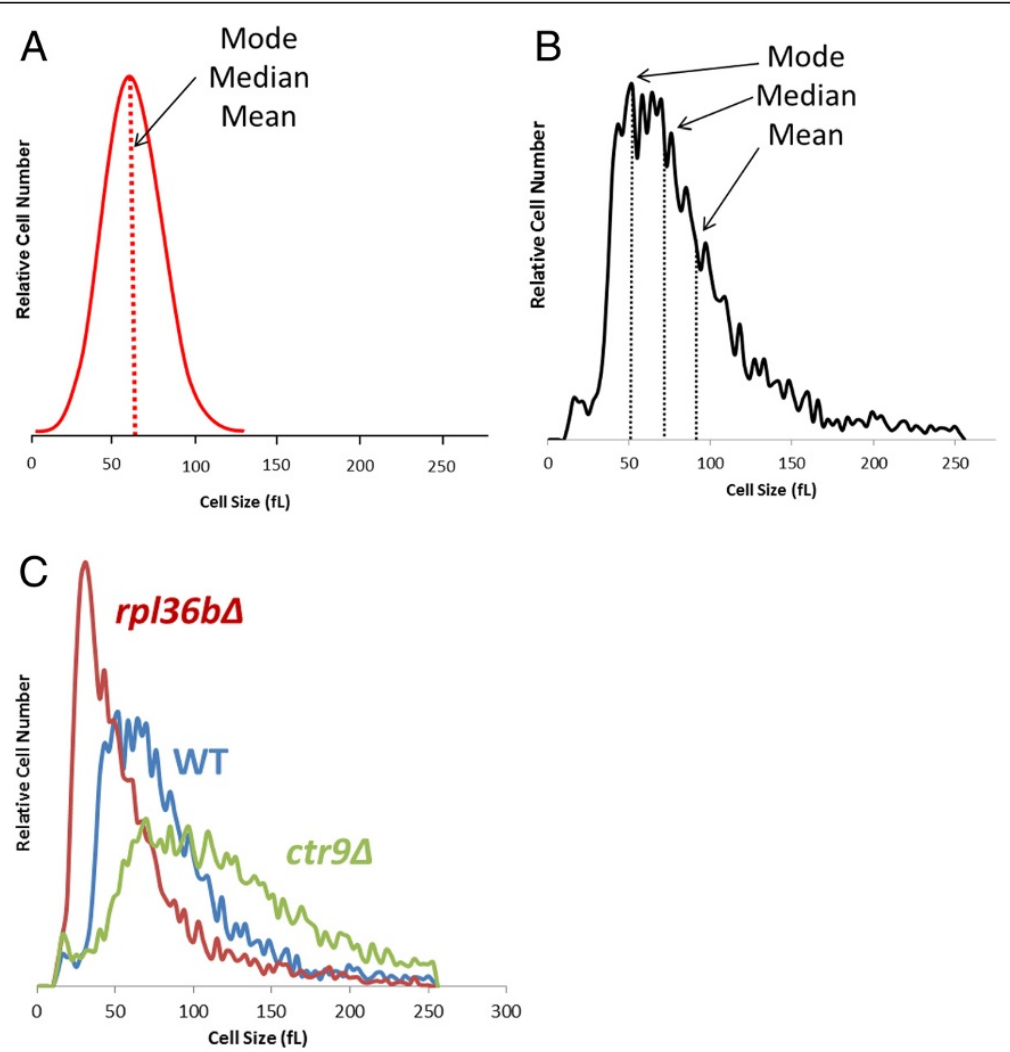

Figure 1 Size distribution curves for budding yeasts. (A) Curve depicts a normal distribution curve with similar mean, median and mode values. (B) Curve depicts a size distribution curve for budding yeasts obtained in logarithmic phase. Unlike normal distributions, yeast cell size curves are usually skewed to the right where the mode is often the smallest value, since $\sim 50 \%$ of the population is comprised of newly born daughter cells. Also, due to the asymmetric nature of cell division and exponential nature of cell growth, the mean value tends to be larger than the median. (C) Coulter counter curves for representative size mutants in the logarithmic phase: whi mutant (rp/36b $)$, wild-type (WT) and uge mutant (ctr9s). 
Table 1 Summary of cell size mutants

\begin{tabular}{|c|c|c|c|c|c|c|c|c|c|}
\hline & Gene & ORF & Cell size (fL) & Budding $\%$ & G1\% & S/G2/M\% & Human homolog & E-value & Function \\
\hline \multicolumn{10}{|c|}{ LOGARITHMIC } \\
\hline & WT & & 101.7 & 56 & 38 & 62 & & & \\
\hline \multirow[t]{7}{*}{ whi } & $r p / 36 b \Delta$ & YPL249C-A & $66.0^{* *}$ & 40 & 62 & 38 & RPL36 & $2 e-26$ & Translation \\
\hline & mrp/49A & YJL096W & $66.8^{* *}$ & 45 & 59 & 41 & RFT1 & 0.16 & Translation \\
\hline & $\cos 1 \Delta$ & YDL069C & $71.2^{* *}$ & 43 & 45 & 55 & TLR5 & 0.28 & Translation \\
\hline & $r p / 42 a \Delta$ & YNL162W & $73.9^{* *}$ & 46 & 50 & 50 & RPL36AL & $2 e-51$ & Translation \\
\hline & & YJR114W & $77.1^{*}$ & 54 & 53 & 47 & - & - & Unknown \\
\hline & $\operatorname{rom} 2 \Delta$ & YLR371W & $80.2^{* *}$ & 60 & 55 & 45 & ARHGEF3 & $3 e-16$ & GEP for Rho \\
\hline & $r p / 16 b \Delta^{\#}$ & YNL069C & $83.5^{*}$ & 52 & 44 & 56 & L13a & $5 e-76$ & Translation \\
\hline \multirow[t]{2}{*}{ uge } & ecm9 9 & YKR004C-A & $135.9^{*}$ & 62 & 37 & 63 & KCNS2 & 0.060 & Cell Wall Organization \\
\hline & $\operatorname{ctr9\Delta }$ & YOL145C & $128.5^{*}$ & 36 & 33 & 67 & CTR9 & $2 e-48$ & Transcription \\
\hline \multicolumn{10}{|c|}{ SATURATED } \\
\hline & WT & & 49.7 & 3 & 96 & 4 & & & \\
\hline uge & $\operatorname{ctr} 9 \Delta$ & YOL145C & $76.8^{*}$ & 11 & 93 & 7 & CTR9 & $2 \mathrm{e}-48$ & Transcription \\
\hline
\end{tabular}

A summary of cell size mutants, grouped together under logarithmic and saturated conditions, is shown. Data includes the gene, open reading frame (ORF) of the gene, mean cell size in femtoliters ( $\mathrm{fL}$ ), budding index values, cell cycle distribution in logarithmic phase obtained by FACS, human homolog, E-values and cellular function associated with each gene. Statistical differences in mean cell size values were calculated using unpaired $t$-test $\left({ }^{* *} \mathrm{p}<0.0001,{ }^{*} \mathrm{p}<0.05\right)$. ${ }^{*}$ All genetic strains are homozygous diploids except for $r p / 16 b \Delta$ which is a heterozygous diploid. Thus, $r p / 16 b \Delta$ is a haploinsufficient cell size mutant. Note that YJR114W is a dubious ORF.

re-made deletions (internal controls) reproduced the expected size phenotype (Additional file 1: Table S1). These included 10 previously reported cell size mutants [26,27] (Additional file 1: Table S1). Of the eight deletions that failed to reproduce the expected size phenotype, two were very close to being significantly larger (Additional file 1: Table S1). Thus, the true reproducibility likely ranges from 94-96\% indicative of the robustness of the approach.

\section{Mutants alter daughter birth size and "critical cell size"}

Analyses of Coulter Counter data only provides size data for the entire population. To evaluate how the size of individual cells vary, we used time lapse photography of single cells over 10-12 hours as previously described [61]. Examination and sizing of individual cells revealed that all seven whi mutants produced virgin daughter cells that are statistically smaller $(\mathrm{p}<0.0001)$ than wild type virgin daughter cells (Figure $2 \mathrm{~A}$ ). In addition, deletion of CTR9 and ECM9 produced statistically larger than normal virgin daughter cells $(\mathrm{p}<0.05)$ (Figure $2 \mathrm{~A})$.

In yeast, cells commit to division after attaining a certain "critical cell size". To observe changes in the "critical cell size" at START, time-lapse microscopy was also used to study the pattern of cell division over time for the new size mutants. For experimental purposes, size at bud emergence was measured for daughter and mother cells and plotted against \% budded. START usually refers to the point at which $50 \%$ of the cell population has budded. For all the seven whi mutants, the size of virgin daughters at START was significantly smaller $(\mathrm{p}<0.0001)$ than in wild type cells (Figure 2B and 2D). In addition, for all seven whi mutants, mother cells progressed past START at a significantly smaller size compared to wild type mother cells (Figure $3 \mathrm{~A}$ and $\mathrm{C}$ ). For the large cell mutants, the situation was exactly the reverse; virgin daughters were born large (Figure 2A), and both daughters (Figure 2C and 2D) and mothers (Figure $3 \mathrm{~B}$ and $\mathrm{C}$ ) progressed past START at a cell size that was significantly larger $(\mathrm{p}<0.05)$ than in wild type cells. These results suggest that the newly identified cell size mutants alter the "critical cell size" at which commitment to cell division occurs.

\section{Cell cycle effects}

Many of the known cell size control genes also strongly affect cell cycle progression [22,29,31,32,62,63]. Thus, flow cytometry and the budding index of cultures were used to assess cell cycle distributions in the newly identified cell size mutants (Table 1). In addition, we were able to directly measure the length of the unbudded (G1phase) and budded (S-G2-M-phases) segments of the cell cycle in all of the cell size mutants from the time lapse studies of single cells (Table 2). From these data, several trends emerged. First, overall cell cycle time was increased in all mutants regardless of their size (Table 2). Second, a considerable increase in the length of G1phase was predominantly responsible for the increase in cell cycle times (Table 2). Third, while G1-phase was increased in all mutants, the degree to which it was affected was extremely variable: ranging from a $0-7.6$ fold increase in mother cells or a 1.3-5.4 fold increase in 


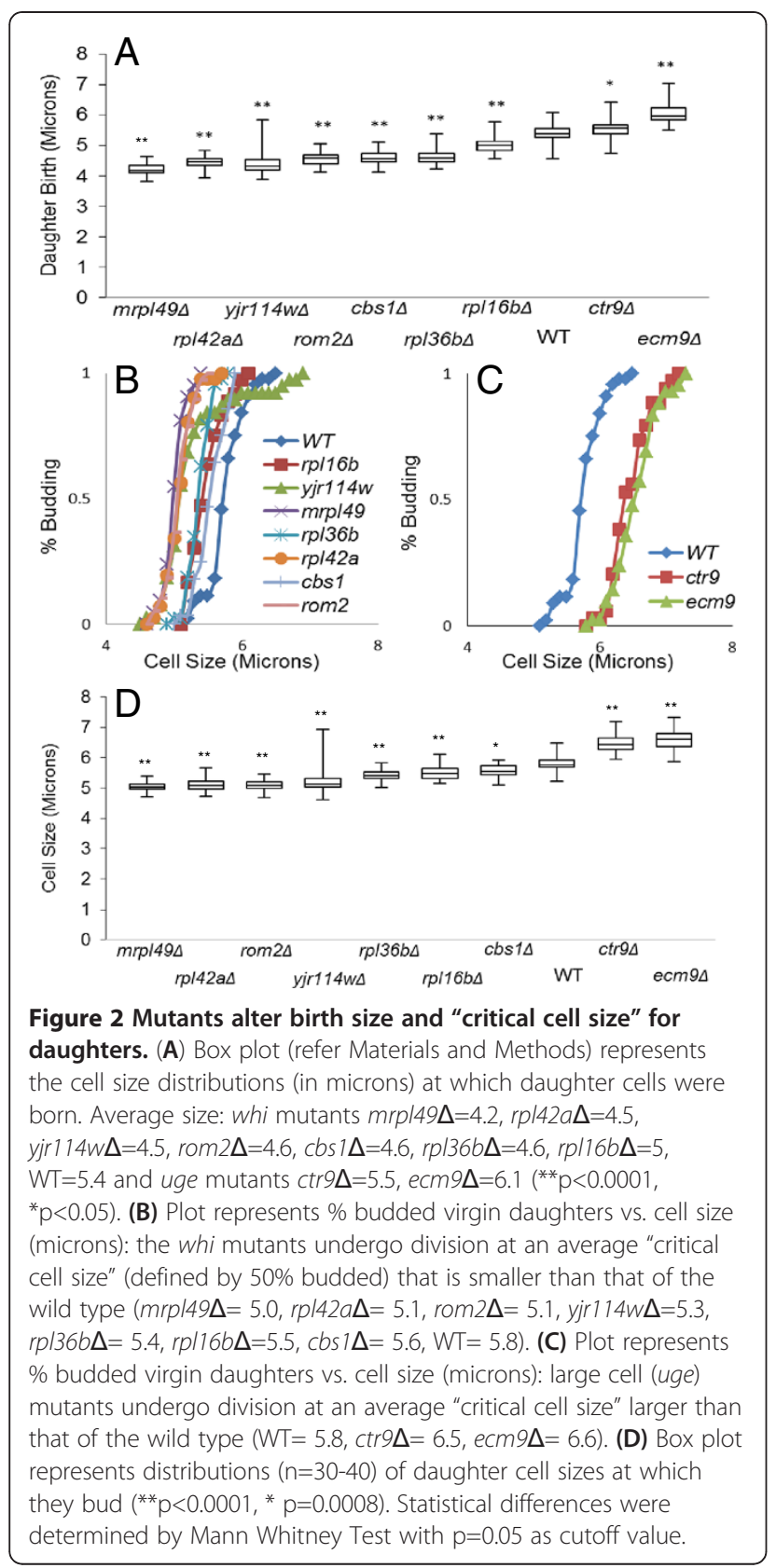

daughters (Table 2). Appropriately, mutants with the shortest G1-phases had, in general, the highest budding indices (Tables 1 and 2). In this respect, only one whi mutant, rom $2 \Delta$, increased the budding percentage compared to that of wild type which would suggest a putative inhibitory role of ROM2 in the START transition. In contrast, the majority of the whi mutants had an increased accumulation of cells in G1-phase compared to the wild type. Such a pattern is characteristic of cells with a slow growth phenotype [35] in which cells display a small size phenotype with extended periods of G1 phase [64].
From the uge mutants identified, $c t r 9 \Delta$ strongly reduces the budding index values to that of the wild type while ecm $9 \Delta$ moderately increased budding in log phase (Table 1). In contrast, the uge mutant ctr9 9 in saturated phase increased the percentage of budded cells and concomitantly decreased the number of cells in G1-phase (Table 1) suggesting that these mutants impeded the ability of cells to exit the cell cycle.

In order to establish any potential hierarchical role of the newly identified cell size mutants in START regulation, double deletion combinations for individual mutants were created with the START activator CLN3; and the START inhibitor, WHI5. In wild type cells, deletion of CLN3 results in a cell cycle delay thereby inducing a large cell size phenotype $[26,27]$. We found that deletion of YJR114W, RPL36B, ROM2 and RPL42A yielded an intermediate size phenotype in combination with deletion of CLN3 (Table 3). However, deletion of MRPL49 and CBS1 did not reduce the size of $\operatorname{cln} 3 \Delta$ cells. These results suggest that the small size phenotype of the mrpl49 $\Delta$ and cbs1 $1 \Delta$ whi mutants is dependent upon CLN3. With respect to the uge mutants, both $c t r 9 \Delta \ln 3 \Delta$ and ecm $9 \Delta \operatorname{cln} 3 \Delta$ double mutants were larger than either haploid alone indicating a synergistic effect (Table 3 and Additional file 1: Table S1). On the other hand, combination of whi5 $\Delta$ with all the whi mutants (except $r p l 42 a \Delta$ ) resulted in double mutants that were smaller than either haploid alone indicative of a synergistic effect. With respect to the uge mutants, ctr9 9 whi5 $\Delta$ double mutant displayed an intermediate size phenotype while ecm $9 \Delta$ whi5 $\Delta$ double mutant was small. Since whi5 5 was epistatic to $e c m 9 \Delta$, the large size phenotype of ecm $9 \Delta$ mutant is most likely dependent upon WHI5 (Table 3 and Additional file 1: Table S1).

Finally, over-expression studies were carried out to determine whether any of the newly identified cell size mutants could function as activators or inhibitors of START. Over-expression of ECM9 resulted in a strong reduction of cell size distribution (Table 4). Furthermore, the increased budding index values along with a higher percentage in S/G2/M phase suggests that Ecm 9 promotes START (Table 4). On the other hand, overexpression of CTR9 increased the budding index values without a concomitant decrease in cell size of the culture. Counter-intuitively, over-expression of six whi mutants also reduced cell size (Table 4). Evidence indicated that over-expression of these whi mutants led to decreased proliferation rates in the majority of cases (data not shown) and some G1-phase delays (Table 4).

\section{Cell growth and cell size homeostasis}

Examination of the known function of the new cell size mutants suggests that reduced protein synthesis and overall growth rate may correlate with decreased cell size. For example, 5 of the 7 whi mutants isolated are 

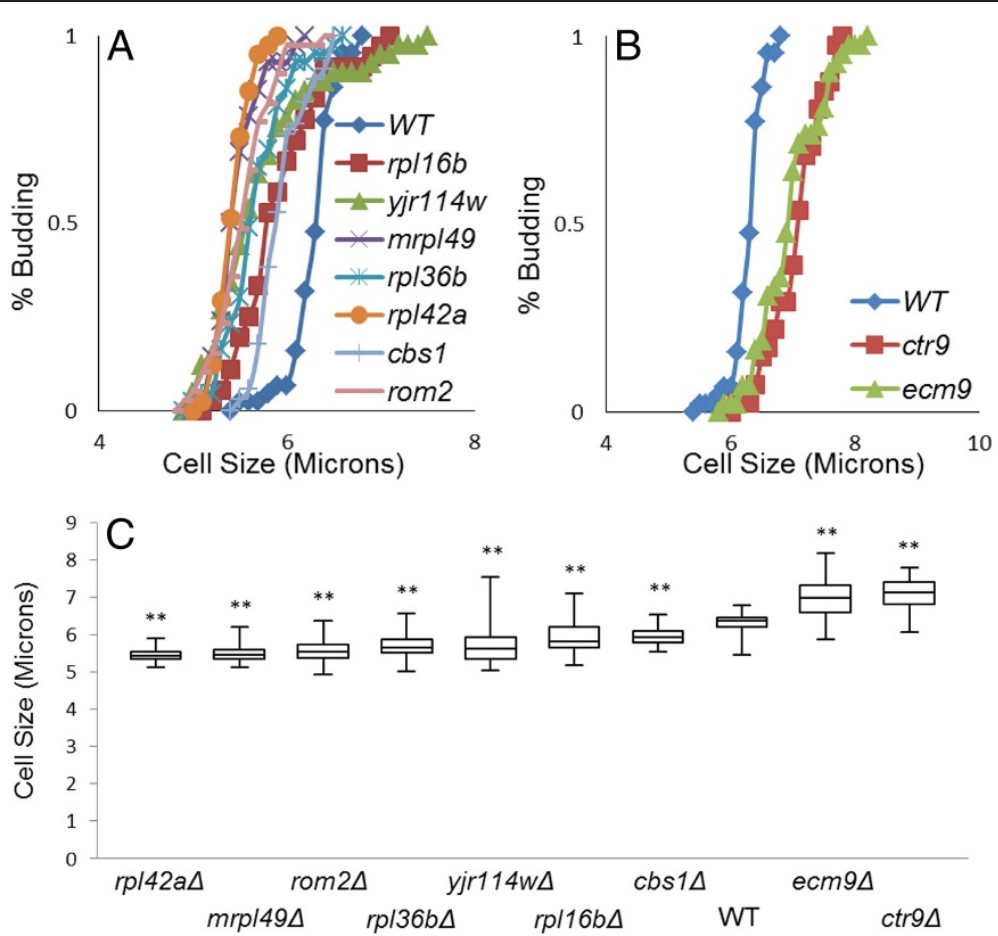

Figure 3 Mutants alter "critical cell size" at START for mothers. (A) The \% of budded mother cells vs. cell size (microns) is plotted: whi mutants undergo division at a "critical cell size" smaller than that of the wild type (rp/42a $\Delta=5.5, m r p / 49 \Delta=5.5, r o m 2 \Delta=5.6, r p / 36 b \Delta=5.7$, yjr $114 w \Delta=5.7, r p / 16 b \Delta=5.9, \operatorname{cbs} 1 \Delta=6.0, W T=6.3$ ). (B) The \% of budded mother cells vs. cell size (microns) is plotted: large cell (uge) mutants undergo division at a "critical cell size" larger than that of the wild type (WT=6.3, ecm9 $\Delta=7.0, c t r 9 \Delta=7.1)$. (C) Box plots represent size distributions $(n=35-45)$ of mother cell populations at which they bud $(* * 0<0.0001)$. Statistical differences were determined by Mann Whitney Test with $p=0.05$ as cutoff value.

Table 2 Summary of cell cycle effects

\begin{tabular}{|c|c|c|c|c|c|c|c|c|c|c|c|c|c|}
\hline \multirow[b]{2}{*}{ Strain } & \multicolumn{5}{|c|}{ Daughter } & \multicolumn{6}{|c|}{ Mother } & \multicolumn{2}{|c|}{ Overall } \\
\hline & Birth size & B1 size & G1 (min) & B2 size & $\mathrm{CT}$ & B1 size & $\mathrm{CT} 1$ & B2 size & $\mathrm{CT} 2$ & B3 size & G1 (min) & $\mathrm{CT}$ & RGR \\
\hline WT & 5.4 & 5.8 & 32 & 6.0 & 83 & 6.3 & 75 & 6.4 & 74 & 6.4 & 4 & 77 & $100 \%$ \\
\hline mrp/49 $\Delta$ & 4.2 & 5.1 & 172 & 5.2 & 167 & 5.5 & 140 & 5.6 & 154 & 5.7 & 30 & 154 & $51 \%$ \\
\hline$r p / 42 a \Delta$ & 4.4 & 5.1 & 94 & 5.4 & 131 & 5.5 & 97 & 5.5 & 115 & 5.6 & 8 & 114 & $58 \%$ \\
\hline yjr114w $\Delta$ & 4.5 & 5.4 & 136 & 5.5 & 183 & 5.8 & 136 & 5.9 & 137 & 6.0 & 25 & 152 & $67 \%$ \\
\hline$r p / 36 b \Delta$ & 4.6 & 5.4 & 131 & 5.6 & 158 & 5.7 & 143 & 5.8 & 139 & 5.8 & 24 & 147 & $67 \%$ \\
\hline $\operatorname{rom} 2 \Delta$ & 4.6 & 5.1 & 89 & 5.3 & 135 & 5.6 & 115 & 5.6 & 111 & 5.7 & 4 & 120 & $64 \%$ \\
\hline $\cos 1 \Delta$ & 4.6 & 5.6 & 141 & 5.9 & 208 & 6.0 & 129 & 6.1 & 150 & 6.2 & 26 & 162 & $69 \%$ \\
\hline$r p / 16 b \Delta$ & 5.0 & 5.5 & 47 & 5.8 & 124 & 5.9 & 94 & 6.0 & 100 & 6.1 & 6 & 106 & $83 \%$ \\
\hline $\operatorname{ctr} 9 \Delta$ & 5.5 & 6.5 & 130 & 6.8 & 153 & 7.1 & 110 & 7.2 & 145 & 7.3 & 20 & 136 & $116 \%$ \\
\hline ecm9s & 6.1 & 6.6 & 41 & 7.0 & 127 & 7.0 & 114 & 7.2 & 107 & 7.3 & 8 & 116 & $155 \%$ \\
\hline
\end{tabular}

Data gathered from microscopic analyses of $>30$ individual cells over a 6-10 hour time course is presented. Cell diameters are in microns. In each case, the birth diameter of daughter cells is shown. In addition, the size at which cells bud for the first time (B1) and subsequent buds (B2, etc.) are also provided. The length of G1-phase is directly measured as the time cells remain unbudded. Cycle time (CT) is measured from the time a cell first buds until its subsequent bud. Overall cycle time (CT) is shown as the average of one daughter CT and the first two mother cell cycle times. The relative growth rate (RGR) is a measure of the total cell volume produced per generation and is determined by calculating the change in volume of mother cells in each generation added, to the volume of daughter cells produced. For volume calculations, cells are assumed to resemble spheres and the formula $4 / 3 \pi r^{3}$ is used. Wild type (WT) cells are set to $100 \%$ and all mutants are subsequently normalized to this value. 
Table 3 Genetic epistasis analyses

\begin{tabular}{|c|c|c|}
\hline & $\operatorname{cln} 3 \Delta$ & whi5s \\
\hline$m r p / 49 \Delta$ & $\uparrow$ & $\bullet$ \\
\hline yjr114w $\Delta$ & + & $\bullet$ \\
\hline$r p / 36 b \Delta$ & + & $\bullet$ \\
\hline$r p / 42 a \Delta$ & + & - \\
\hline $\operatorname{cbs} 1 \Delta$ & $\uparrow$ & $\bullet$ \\
\hline $\operatorname{rom} 2 \Delta$ & + & $\bullet$ \\
\hline$r p / 16 b \Delta$ & NA & NA \\
\hline ecm9 & $\bullet$ & $\uparrow$ \\
\hline ctr9 & $\bullet$ & + \\
\hline
\end{tabular}

Genetic epistasis analysis with $c \ln 3 \Delta$ and whi5 $\Delta$. Double deletion combinations were created for the new logarithmic phase size mutants with $\operatorname{cln} 3 \Delta$ (uge mutant) and whi5 $\Delta$ (whi mutant). Haploids were analyzed for the cell size phenotype. Table represents the pair wise genetic relationships: Intermediate $(+)$, epistatic $(\uparrow)$ (the gene pointed to by the arrow masked the size phenotype of the other deletion), synergistic (-), no effect (-). Epistasis was operationally defined as an average cell size for double mutants within $+/-5 \%$ of size of either single mutant. Synergistic effects refer to combinatorial cell sizes that are either substantially larger or smaller than each single mutant. Intermediate refers to combinatorial cell sizes that lie between the size of each single mutant. Since RPL16B is an essential gene, it could not be analyzed in these studies. Size values with statistics can be found in Additional file 1: Table S1.

involved in general protein translation (Table 1). Three

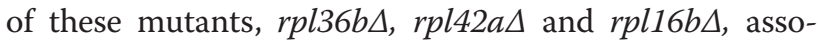
ciate with the large ribosomal subunit in the ribosome assembly process [65] while MRPL49 and CBS1 are involved in mitochondrial protein synthesis [66]. Since previous screens for cell size mutants have revealed that a significant number of whi mutants whose gene products normally function in protein synthesis or ribosome biogenesis [26,27], the growth rate of individual cells was determined from time course data. By measuring the rate of cell size increase in mother cells and the size of buds produced, we were able to determine the

Table 4 Over-expression analyses

\begin{tabular}{ccccccc}
\hline WT + & Mean & N & SE & G1\% & S/G2/M\% & Budding index \\
\hline Empty Vector & 78 & 11 & 1 & 56.99 & 40.56 & 44.3 \\
ECM9 & $62^{* *}$ & 11 & 1 & 52.21 & 47.79 & 60.3 \\
CTR9 & 80 & 14 & 1 & 54 & 46 & 65.7 \\
MRPL49 & $68^{* *}$ & 11 & 2 & 52.38 & 47.62 & 51.9 \\
YJR114W & $68^{*}$ & 13 & 2 & 72.53 & 27.47 & 44.4 \\
RPL42A & $68^{* *}$ & 13 & 1 & 52.24 & 47.76 & 57.7 \\
RPL16B & $72^{* *}$ & 13 & 1 & 44.31 & 55.69 & 62.3 \\
CBS1 & $69^{*}$ & 14 & 2 & 72.64 & 24.46 & 45.7 \\
RPL36B & 73 & 6 & 4 & 59.31 & 40.09 & 41.6 \\
\hline
\end{tabular}

Over-expression analysis in wild type cells. This table illustrates the effects of over-expressing the new size mutant genes in wild type yeast cells. Data includes the average cell size from logarithmic cultures, number of replicates, standard error, \% of cells in G1 and S/G2/M phases as determined by flow cytometry, and the budding index values. Statistical differences in mean cell size values were calculated using unpaired $t$-test $\left({ }^{* *} \mathrm{p}<0.0001,{ }^{*} \mathrm{p}<0.0051\right)$. All analyses were carried out in -Ura Raf/Gal media using GAL-inducible vectors. Vector alone (pB63) was used as a control. Note: We were unable to generate a GAL-ROM2 inducible vector. average relative growth rate for both whi and uge mutants in each generation. In doing so, we found all seven whi mutants had average growth rates that were $17-49 \%$ less than wild type cells (Table 2). In contrast, the average growth rate was higher in both large cell mutants (Table 2). These results suggest that growth rates correlate well with cell size phenotypes.

\section{Discussion}

\section{Identification and impact of new cell size mutants}

Cell size homeostasis is attained by a highly intricate relationship between growth and proliferation. Previous studies suggest that growth is rate-limiting for commitment to cell division such that cells must attain a "critical cell size" prior to START transition [5,6,15]. To better understand the global mechanism behind cell size control, two systematic genome-wide genetic screens were carried out ten years ago to detect cell size mutants from both log phase and saturated cultures [26,27]. Many of the identified cell size genes are directly associated with START and are linked to CLNs [27]. Significantly, the yeast ortholog of the pRB tumor suppressor was identified in the previous screens [26,27]. In addition, key regulators of cell growth and ribosome biogenesis (e.g. Sfp1 and Sch9) were shown to be strong whi mutants [26]. Such analyses proved to be highly valuable in the detailed characterization of cell size machinery. Since the original screens were conducted, a second generation yeast deletion collection has been constructed containing hundreds of new knockout strains and re-created deletions (n.b. most of these deletions were remade to correct quality control issues such as a partial rather than complete ORF deletion). The objective of this study was to expand the genome-wide systematic screen concept by evaluating the $\sim 800$ newly made ORF deletions for size mutants. In so doing, 9 cell size mutants were identified in the logarithmic phase cultures and 1 cell size mutant was identified in saturated cultures. Of the $\sim 140$ ORF deletions that were remade, $>94 \%$ of the strains reproduced the original phenotype including both strong whi (e.g. sch94) and large cell phenotypes (e.g. ccr4 4 ). Importantly, screening of the re-made ORF deletions yielded four new size mutants, supporting the notion that some deletions in the original collection did in fact retain some gene function. In total, seven new whi and two new large cell mutants were identified, and after completion of this work, $\sim 97 \%$ of the yeast genome has been now screened for cell size mutants.

In the previous screens, many of the whi mutants identified involved the deletion of genes that function in ribosome biogenesis and translation [26,27]. Of note, 5 of the 7 newly identified whi mutants are involved in the general process of translation supporting the hypothesis 
that robust ribosomal biogenesis is integral for cell growth and is a prerequisite for normal cell cycle progression $[39,40]$. One whi mutant, yjr114wd, has an unknown function; however its phenotype may be due to loss of function of the overlapping RSM7 ORF. The RSM7 gene encodes a mitochondrial ribosomal subunit that when deleted also yields a small cell phenotype [26]. A final whi mutant, rom $2 \Delta$, is also clearly involved in the regulation of cell growth. Rom2 is a GEF protein which interacts with the TOR signaling pathway in sensing nutrients from the external environment [67]. TOR is implicated to play a major role in the overall synthesis of proteins and inhibiting its activity strongly affects cell size phenotypes [68,69]. Also, Rom2 activates Rho1 GTPase and $r h o 1^{t s}$ mutants have been reported to reduce the cell volume of both mother cells at G1/S transition and daughter cells at birth [70]. Interestingly, premature CLN2 expression had been observed in rho1-3 mutants and may help explain why rom $2 \Delta$ mutants display a small size with higher budding index. Amongst the uge mutants isolated, CTR9 plays a direct role in the transcription of CLNs through association with the Paflp complex [71] and ecm $9 \Delta$ strains exhibit alterations in cell surface biosynthesis due to defects in $\beta$ 1,3-glucan synthesis [72]. Significantly, 8 of the 9 newly identified log phase mutants have putative human homologs (Table 1) suggesting that cell size control may be evolutionary conserved.

Initial investigations of the newly identified cell size mutants reveal that all of the genes identified impact cell size by altering cell growth rates. Herein, we report that critical cell size at START is reduced in 7/7 whi mutants in both daughter and mother cells while cell growth is also decreased in all whi mutants. Similarly, critical cell size at START is increased in both large cell mutants while the rate of cell growth is clearly elevated in both ecm $9 \Delta$ and ctr9 $9 \Delta$ cells. Indeed, elegant work done by Jorgensen $e t$ al. elucidated a potential link between ribosome biogenesis, cell growth, and START which may be predominantly responsible for the observed cell size defects [37], and a potential connection between newly identified size mutants and this work is discussed below.

A comparison between current results and the outcome of the previous two systematic cell size screens reveals striking similarities. First, as previously observed, considerably more size mutants were identified from log phase as compared to saturated cultures [26,27]. Second, most size mutants identified in log phase were not also detected as size mutants in saturated cultures [26,27]. The reason for these observations is not clear at this time but does indicate that different mechanisms impact cell size in log phase as compared to saturated cultures. Finally, the frequency of size mutants detected was very similar and with $97 \%$ of the genome screened, it is clear that $\sim 6 \%$ of the yeast genome is involved in log phase cell size control as opposed to largely different subset of genes (only $\sim 1 \%$ of the genome) that modulates cell size in saturation.

\section{At the crossroads: cell size regulation and cell cycle progression}

One of the primary goals of systematic genetic size screens was to identify genes that regulate START. For example, in budding yeast, START is dependent on the activity of the G1-phase cyclin CLN3 and its cyclindependent kinase Cdc28 [28,73-75]. CLN3 can regulate the rate of accumulation of CLN1/CLN2 and alter the "critical cell size" at START [22,23,76]. Deletion of CLN3 results in delayed accumulation of CLN1/CLN2 causing the cells to enter cell division at a much larger cell volume. G1-phase cyclins CLN1/CLN2 dramatically alter the "critical cell size" and genes which regulate their transcription have been isolated [22,29,31,32,62,77,78]. Since the role of CLN3 and WHI5 in cell cycle commitment has been well characterized in yeast in addition to the function of their orthologs in higher eukaryotes [47], we wanted to examine the role of newly identified size mutants with START regulation. To accomplish this, we created double mutants between all newly isolated size mutants with either the deletion of an inhibitor (e.g. whi5 $\Delta$ ) or an activator (e.g. $\operatorname{cln} 3 \Delta$ ) of START. In so doing, we found that all of the whi mutants, except rpl42a 4 , had a synergistic effect on cell size when combined with whis $\Delta$ (i.e. double mutants were smaller than single mutants). Most likely, the size effects in these whi mutants are mediated through a pathway which is independent of WHI5. This result infers the existence of an additional inhibitor to START. A parallel inhibitor to WHI5 has been isolated [47], but its relationship with the newly identified whi mutants is not known. These results are intriguing in light that the yeast counterparts of the mammalian p16 and p21 cyclin dependent inhibitors have not yet been identified. Most of the new whi mutants when combined with $\operatorname{cln} 3 \Delta$ produced intermediate size phenotypes; however, the large cell phenotype of $\operatorname{cln} 3 \Delta$ was epistatic to mrpl49 $\Delta$ and $\operatorname{cbs} 1 \Delta$ suggesting that these genes function upstream of $\mathrm{Cln} 3$.

The large cell size of ctr9 9 mutant is partially dependent on the activity of WHI5 since double mutants display additive effects. While CTR9 (Cln Three Requiring) was first identified in a screen for mutants which required a functioning copy of CLN3 for viability [29], unlike previous studies [71], we find that $\operatorname{cln} 3 \Delta \operatorname{ctr} 9 \Delta$ mutants are viable albeit slowly dividing very large cells. This result is likely due to different strain backgrounds. On the other hand, over-expressing CTR9 did not cause cell size changes but increased the budding index of the population. G1-phase cyclins regulate bud emergence in budding yeasts and localization of CLN2 in the 
cytoplasm is responsible for this process [79,80]. Although CTR9 is proposed to have a direct role in CLN2 transcription, it is somewhat surprising that the budding index of cells increases but cell size does not decrease. However, deletion of WHI5 in ecm9 9 mutants results in very small cells. These results suggest that Ecm 9 functions upstream of Whi5 and may regulate START by modulating Whi5 activity. Like cln $3 \Delta$ ctr $9 \Delta$ mutants, $\operatorname{cln} 3 \Delta e c m 9 \Delta$ cells are also slowly dividing very large cells indicating a general delay in progression past START in ecm9 94 mutants. Indeed, over-expression of ECM9 resulted in a dramatic reduction in cell size as well as a strong decrease in the percent of unbudded G1-phase cells supporting the notion that ECM9 directly promotes progression past START.

Over-expression of Clns prematurely promotes cell cycle progression. The end result is the production of a population of small cells with a smaller percentage of cells in G1-phase. Since most cell size mutants appear to interact directly or indirectly with the START machinery (e.g. CLN transcription is induced at a smaller than normal size in whi mutants and vice versa), the logical assumption is that most whi mutants would advance cell cycle progression and thereby reduce the percentage of cells in G1-phase. Conversely, large cell mutants might be expected to delay cell cycle progression and thereby increase the percent of G1-phase cells. This concept was recently investigated on a genomic-wide scale. Strikingly, Hoose et al. found virtually no correlation between cell size mutants and cell cycle distributions [39]. For example, the majority of cells showing a dramatically increased or decreased percent of G1-phase cells were not cell size mutants [39]. Moreover, the majority of cell size mutants failed to display altered cell cycle distributions [39]. Our current results largely corroborate these findings. The apparent disconnect between cell size regulation and cell cycle progression was reinforced by our over-expression studies. While over-expression of 7/8 of our cell size mutants reduced cell size, over-expression of only $2 / 7$ of these genes dramatically altered cell cycle distributions, which stands in contrast to another study where changes in cell cycle progression were shown to be predominantly due to gain of function alterations [81]. Thus, despite the fact that most whi mutants appear to advance the timing of CLN transcription, they do not appear to advance START. The reasons and mechanisms behind this disconnect warrants considerably more investigation.

\section{Future perspectives: the slow growth conundrum and a role for cell size in lifespan regulation?}

Evidence suggests that a minimal threshold level of Clns links cell size to START [38]. In this respect, decreasing or delaying Cln expression concomitantly slows cell cycle progression to produce abnormally large cells. Therefore, precise coordination between growth and proliferation is indispensable for cell size homeostasis. Since Clns are inherently and constitutively highly unstable proteins $[82,83]$, steady state Cln levels would seem to be an excellent measure of the synthetic capacity of a cell and thereby provide a means to link cell growth to cell division [4,13,14,44]. As expected, Cln levels are low in slowly growing cells. However, counterintuitively, slowly growing cells require considerably lower levels of Cln to progress past START [38]. Conversely, rapidly growing cells require high levels of $\mathrm{Cln}$ to bud [38]. The reasons for these observations are still not known, but a thorough investigation of the relationship between cell size mutants and the regulation of $\mathrm{Cln}$ expression and abundance may provide some clarity to this conundrum. Another possibility is that the rate of protein synthesis is the major determinant of cell size. Dissection of the relationship between cell size mutants, Cln expression, and cell cycle progression will be a key step in the elucidation of this issue.

Finally, recent studies have demonstrated that cell size may be relevant to the rate at which yeast cells age [61]. For example, many of the size mutants exhibit lifespan phenotypes dependent on the size at birth, i.e. small cells have an extended lifespan compared to cells that are big in size [61]. A similar correlation was obtained with size mutants obtained from this screen. rpl42a $\Delta$, a whi mutant, had an extended lifespan compared to the wild type [61]. Moreover, two other whi mutants, $\operatorname{rom} 2 \Delta$ and $r p l 16 b \Delta$, identified in this screen are also reported to have a prolonged lifespan $[84,85]$. Although not all mutants that affect cell size have a lifespan phenotype, the identification of new size mutants will aid in the continued investigation into the relationship between size and replicative lifespan.

\section{Conclusions}

Proper coordination between cell growth and proliferation is essential for normal propagation, development and differentiation. Multiple studies have outlined the significance of such coordination in cell size homeostasis. To understand the mechanisms of cell size control, two genome wide screens had been carried out to identify cell size mutants. Many genes from these screens have now been established in START regulation. To complete the initial screen and identify previously unknown cell size genes, nearly 800 new diploid strains were sized in logarithmic and saturation phase. Ten new strong cell size mutants were thus identified. Nearly all of the new whi mutants function in the translation process thus further supporting the integral role of growth in cell cycle commitment. Genetic analyses suggest that CLN3 is required to mediate the size effects in mrpl49A and cbs $1 \Delta$ small mutants. 
Finally, ECM9 was found to be strongly associated with START. After completion of this study, 97\% of the yeast genome has now been screened for cell size mutants. The consistency of the type and function of the size mutants identified here reaffirms the robustness of genome wide screen approaches and augments the current and valuable database of cell size control genes.

\section{Materials and methods \\ Cell size analysis}

YKOv2, containing the homozygous and heterozygous diploid S. cerevisiae deletion strain sets, were obtained from OPEN BIOSYSTEMS. To assay cell size in saturation, five $\mu \mathrm{l}$ of each strain was spotted onto 96 grid points on $2 \%$ YPD plates and incubated at $30^{\circ} \mathrm{C}$ for 3 days. A small amount of each colony was suspended in $500 \mu$ l of sterile water. Subsequently, ten $\mu \mathrm{l}$ of this dilution was resuspended in $10 \mathrm{ml}$ of Isoton II (Beckman-Coulter), and cell size was determined using the Z2 Coulter Counter Channelyzer (Beckman-Coulter). For logarithmic phase cell size readings, YPD cultures containing $1-3 \times 10^{6}$ cells $/ \mathrm{ml}$ were grown to a density of $1-4 \times 10^{7} \mathrm{cells} / \mathrm{ml}$, and cell size was measured as discussed above. The geometric mean, median and mode values were recorded for 767 strains in the logarithmic phase and 772 strains in the saturation phase (Additional file 1: Table S1). For statistical analysis, outliers $(+/-2$ standard deviations for all 3 parameters; mean, median and mode) were identified as cell size mutants. To ensure stringency, this selection was applied to data obtained from homozygous, heterozygous, and combined data (homozygous + heterozygous) for all the deletion strains (Additional file 1: Table S1). Using this approach, 32 deletion strains were initially identified as outliers. Of these, 10 strains had already been mentioned

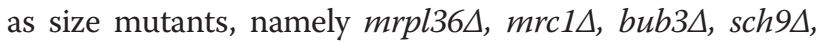
$y d r 417 c \Delta, c c r 4 \Delta, b c m 2 \Delta$, pop $2 \Delta, y d r 433 w \Delta$ and bud $22 \Delta$. From the remaining strains, ten significantly reproduced their size phenotypes after at least three independent measurements (Additional file 1: Table S1). PCR amplification of the unique barcodes was carried out to confirm the absence of the genes in the newly identified size mutants (data not shown).

\section{Cell cycle analysis}

Cells from logarithmic phase and saturated cultures were harvested and fixed in ethanol overnight at $4^{\circ} \mathrm{C}$. Cells were then re-suspended in $50 \mathrm{mM}$ sodium citrate, washed and re-suspended again in the same buffer, treated with RNAse A (final concentration $=0.25 \mathrm{mg} / \mathrm{ml}$ ) for 1 hour at $50^{\circ} \mathrm{C}$ followed with Proteinase $\mathrm{K}$ (final concentration $=0.5 \mathrm{mg} / \mathrm{ml}$ ) for 1 hour at $50^{\circ} \mathrm{C}$. Cells were then stained with Propidium Iodide solution (final concentration $=16 \mathrm{mg} / \mathrm{ml}$ ) and cell cycle distributions were analyzed using the Epics XL (Beckman-Coulter) flow cytometer. Microscopic measurements of $>30$ individual cells were used to calculate cell cycle time (CT) defined as the time at which a cell first budded to the time at which the cell gave rise to the subsequent bud. The overall Cycle Time (CT) was calculated by averaging two mother cell CTs with one daughter cell CT (Table 2). Budding index values were calculated using five $\mu$ of the same samples. A minimum of 200 yeast cells were observed microscopically using a phase contrast microscope (Zeiss AxioLab) with a 40X objective. The number of budded and unbudded cells was recorded, and the budding index values were calculated. BLAST software from the National Center for Biotechnology Information (NCBI) was used to identify conserved human homologs.

\section{Microscopic analysis of cell size}

Time-lapse photomicroscopy of $>30$ individual cells was used to determine virgin daughter birth size and the "critical cell size" at which the size mutants enter division as described previously [61]. Subsequently, the percent of budded cells was plotted as a function of cell size. Box plots illustrate the distribution of cell sizes for the respective deletion strains. The rectangle includes the range of sizes spanning the first quartile to the third quartile. The horizontal band within the box represents the median value while the whiskers on the top and bottom represent the maximum and minimum values of the range respectively. Mann Whitney statistical tests (GraphPadInStat Version 3.10) were used to evaluate the significance of cell size differences.

\section{Genetic analyses}

Double mutants for epistasis analyses were obtained by mating MAT alpha cln3 (KanMX::Leu2) and whi5 (KanMX::Leu2) haploids with MAT a cell size mutants (confirmed by Coulter counter and PCR analyses). At least 2 individual colonies for each double mutant was sized in the logarithmic phase (as described above) and the average calculated as shown in Additional file 1: Table S1. PCR amplification of the unique barcodes was carried out to confirm the respective gene deletions. For over-expression analyses, GAL constructs were created using the pYES-DEST52 Gateway Vector System (Invitrogen). Primers for ORF amplification were designed as per the guidelines provided by Invitrogen Life Technologies pENTR Directional TOPO Cloning Kits (Version E). A PCR reaction typically included 100ng DNA template, 2-5 $\mu$ l of Pfu Turbo DNA Polymerase (Stratagene), $100 \mathrm{pm}$ of each primer, $8 \mu \mathrm{l}$ of 10X Pfu buffer and $10 \mu \mathrm{l}$ $25 \mathrm{mM}$ dNTPs. Standard PCR cycling conditions were: (A) $2 \mathrm{~min}$ at $95^{\circ} \mathrm{C}$ for denaturation, (B) $30 \mathrm{sec}$ at $95^{\circ} \mathrm{C}$ for denaturation, (C) $30 \mathrm{sec}$ at $50^{\circ}-55^{\circ} \mathrm{C}$ for annealing, (D) $1-3 \mathrm{~min}$ at $72^{\circ} \mathrm{C}$ for extension and (E) $5 \mathrm{~min}$ at $72^{\circ} \mathrm{C}$ as the final extension step, with steps (B)-(D) steps 
repeating 40-45 times. The amplified bands were then excised, from a $1 \%$ agarose gel with $0.5 \mu \mathrm{g} / \mathrm{ml}$ of ethidium bromide, with the help of QIAEX kits (QIAGEN, Valencia, CA). Cloning procedures for integration into the pYES-DEST52 gateway vector was followed as per Invitrogen instructions. For over-expression of CTR9, GAL1-CTR9 vector was obtained from Thermo Scientific Open Biosystems Yeast ORF Collection with BG1805 as the backbone vector. Due to the large size of ROM2 ( 4Kb), cloning of its ORF was not successful. All $G A L$ over-expression vectors were confirmed by restriction digestion. Transformation of yeast was carried out as described previously [86] using -URA as a selectable marker. Subsequently, three individual colonies for each were then cultured overnight in -Ura Raf/Gal media (1\% Raffinose $+1 \%$ Galactose) and the samples were sized in the logarithmic phase. Simultaneously, samples were isolated to calculate the budding index and perform flow cytometry to determine the cell cycle distribution. Rescue experiments were carried out in the respective deletion strains to confirm ORF functionality of over-expression plasmids.

\section{Additional files}

Additional file 1: Table S1. The tabs represent the following data. Hom. LOG: Average mean, median and mode values for the sizing of 299 homozygous diploid strains in the logarithmic phase. Het. LOG: Average mean, median and mode values for the sizing of 468 heterozygous diploid strains in the logarithmic phase. Hom. SAT: Average mean, median and mode values for the sizing of 303 homozygous diploid strains in the saturation phase. Het. SAT: Average mean, median and mode values for the sizing of 469 heterozygous diploid strains in the saturation phase. (Hom + Het) LOG: Average mean, median and mode values for the sizing of 767 diploid strains in the logarithmic phase (299 homozygous diploids +468 heterozygous diploids). (Hom + Het) SAT: Average mean, median and mode values for the sizing of 772 diploid strains in the saturation phase (303 homozygous diploids +469 heterozygous diploids). New cell size mutants: Statistical analysis for cell size of the newly identified size mutants in Table 1. Size mutant failures: Statistical analysis for cell size of the 14 mutants which failed to repeat the size phenotypes. \% Repeatability: Comparative cell size analysis of the overlapping 144 newly constructed deletion strains with the previous screens. Epistasis size values: Logarithmic phase mean cell size readings for the epistatic combinations.

Additional file 2: Figure S1. Cell size analyses of yeast deletion strains. (A) Total of 767 deletion strains (homozygous+heterozygous) were sized in the logarithmic phase. Each data point represents the number of strains whose size falls in a $5 \mathrm{fL}$ bin. The two curves represent the geometric mean (diamond) and median (square) of the cell sizes. Upper and lower size limits are indicated by dashed lines and 95\% of strains had mean cell sizes within the range of $82.7 \mathrm{fL}$ and $118 \mathrm{fL}( \pm 2 \mathrm{SD}$ of the average mean cell size). WT mean cell size (104.1fL) is depicted by the arrow. (B) Total of 772 deletion strains (homozygous+heterozygous) were sized in the saturation phase. Each data point represents the number of strains whose size falls in a $5 \mathrm{fL}$ bin. The two curves represent the geometric mean (diamond) and median (square) of the cell sizes. Upper and lower size limits are indicated by dashed lines and 95\% had mean cell sizes within the range of $38.8 \mathrm{fL}$ and $62.8 \mathrm{fL}$ ( $\pm 2 \mathrm{SD}$ of the average mean cell size). WT mean cell size ( $48.8 \mathrm{fL})$ is depicted by the arrow.

Additional file 3: Figure S2. Cell size distribution curves in saturation phase. Geometric mean distribution curves are represented for the strains studied. Each data point represents the number of strains whose size falls in a $5 \mathrm{fL}$ bin. (A) Screen carried out in the year 2002 (Mean cell size = $50.8 \mathrm{fL}$ ). (B) Analysis of the new strains (Mean cell size $=50.8 \mathrm{fL}$ ).

\section{Competing interests}

The authors declare that they do not have any competing interests.

\section{Authors' contributions}

$\mathrm{HD}$ and BLS designed the study. HD drafted the manuscript and carried out the size analysis, over-expression studies, knockout strain construction and epistasis analysis. HH performed the microscopic analysis. JW, LA and JS participated in plasmid isolation, yeast strain constructions and confirmations. TK and AM conducted the over-expression analyses. All authors read and approved the final manuscript.

\section{Authors' information}

$\mathrm{HD}$ is a PhD graduate. JW is a PhD candidate. $\mathrm{HH}$ is the laboratory technician. LA is a graduate from Texas Tech University (TTU) with a BS degree in Cell and Molecular Biology. JS is currently pursuing her BS degree in Electrical Engineering at TTU. TK is a pediatric intensivist currently pursuing his MS in Cell and Molecular Biology. AM is a third year medical student at TTUHSC. BLS is an Associate Professor at TTUHSC.

\section{Author details}

${ }^{1}$ Department of Cell Biology and Biochemistry, Texas Tech University Health Sciences Center, 3601 4th St Rm. 5C119, Lubbock, TX 79430, USA. ${ }^{2}$ Texas Tech University, Howard Hughes Medical Institute, Lubbock, TX, USA.

Received: 19 September 2012 Accepted: 4 December 2012

Published: 12 December 2012

\section{References}

1. Cook M, Tyers M: Size control goes global. Curr Opin Biotechnol 2007, 18:341-350.

2. Leevers SJ, McNeill H: Controlling the size of organs and organisms. Curr Opin Cell Biol 2005, 17:604-609.

3. Edgar BA, Kim KJ: Cell biology. Sizing up the cell. Science 2009, 325:158-159.

4. Jorgensen $P$, Tyers $M$ : How cells coordinate growth and division. Current biology: CB 2004, 14:R1014-R1027.

5. Johnston GC, Pringle JR, Hartwell LH: Coordination of growth with cell division in the yeast Saccharomyces cerevisiae. Exp Cell Res 1977, 105:79-98.

6. Hartwell LH: Saccharomyces cerevisiae cell cycle. Bacteriol Rev 1974, 38:164-198.

7. Pardee $A B$ : A restriction point for control of normal animal cell proliferation. Proc Natl Acad Sci U S A 1974, 71:1286-1290.

8. Hartwell LH, Culotti J, Pringle JR, Reid BJ: Genetic control of the cell division cycle in yeast. Science 1974, 183:46-51.

9. Tzur A, Kafri R, LeBleu VS, Lahav G, Kirschner MW: Cell growth and size homeostasis in proliferating animal cells. Science 2009, 325:167-171.

10. Killander D, Zetterberg A: Quantitative Cytochemical Studies on Interphase Growth. I. Determination of DNA, Rna and Mass Content of Age Determined Mouse Fibroblasts in Vitro and of Intercellular Variation in Generation Time. Exp Cell Res 1965, 38:272-284.

11. Zetterberg A, Killander D: Quantitative cytochemical studies on interphase growth. II. Derivation of synthesis curves from the distribution of DNA, RNA and mass values of individual mouse fibroblasts in vitro. Exp Cell Res 1965, 39:22-32.

12. Elliott SG, McLaughlin CS: Rate of macromolecular synthesis through the cell cycle of the yeast Saccharomyces cerevisiae. Proc Natl Acad Sci U S A 1978, 75:4384-4388.

13. Rupes I: Checking cell size in yeast. Trends in genetics: TIG 2002, 18:479-485.

14. Turner JJ, Ewald JC, Skotheim JM: Cell size control in yeast. Current biology: CB 2012, 22:R350-R359.

15. Fantes PA, Grant WD, Pritchard RH, Sudbery PE, Wheals AE: The regulation of cell size and the control of mitosis. J Theor Biol 1975, 50:213-244.

16. Wells WA: Does size matter? J Cell Biol 2002, 158:1156-1159. 
17. Dolznig H, Grebien F, Sauer T, Beug H, Mullner EW: Evidence for a sizesensing mechanism in animal cells. Nat Cell Biol 2004, 6:899-905.

18. Grebien F, Dolznig H, Beug H, Mullner EW: Cell size control: new evidence for a general mechanism. Cell Cycle 2005, 4:418-421.

19. Cooper S: Control and maintenance of mammalian cell size. BMC Cell Biol 2004, 5:35

20. Conlon I, Raff M: Differences in the way a mammalian cell and yeast cells coordinate cell growth and cell-cycle progression. J Biol 2003, 2:7.

21. Nurse $P$, Thuriaux $P$, Nasmyth $K$ : Genetic control of the cell division cycle in the fission yeast Schizosaccharomyces pombe. Molecular \& general genetics: MGG 1976, 146:167-178.

22. Nash R, Tokiwa G, Anand S, Erickson K, Futcher AB: The WHI1+ gene of Saccharomyces cerevisiae tethers cell division to cell size and is a cyclin homolog. EMBO J 1988, 7:4335-4346.

23. Cross FR: DAF1, a mutant gene affecting size control, pheromone arrest, and cell cycle kinetics of Saccharomyces cerevisiae. Mol Cell Biol 1988, 8:4675-4684.

24. Nurse P: Genetic control of cell size at cell division in yeast. Nature 1975 , 256:547-551.

25. Tyers M, Tokiwa G, Nash R, Futcher B: The Cln3-Cdc28 kinase complex of $\mathrm{S}$. cerevisiae is regulated by proteolysis and phosphorylation. EMBO $\mathrm{J}$ 1992, 11:1773-1784

26. Jorgensen P, Nishikawa JL, Breitkreutz BJ, Tyers M: Systematic identification of pathways that couple cell growth and division in yeast. Science 2002, 297:395-400.

27. Zhang J, Schneider C, Ottmers L, Rodriguez R, Day A, Markwardt J, Schneider BL: Genomic Scale Mutant Hunt Identifies Cell Size Homeostasis Genes in S. cerevisiae. Current biology: CB 2002, 12:1992-2001

28. Tyers M, Tokiwa G, Futcher B: Comparison of the Saccharomyces cerevisiae $\mathrm{G} 1$ cyclins: $\mathrm{Cln} 3$ may be an upstream activator of $\mathrm{Cln} 1, \mathrm{Cln} 2$ and other cyclins. EMBO J 1993, 12:1955-1968.

29. Di Como CJ, Chang H, Arndt KT: Activation of CLN1 and CLN2 G1 cyclin gene expression by BCK2. Mol Cell Biol 1995, 15:1835-1846.

30. Epstein CB, Cross FR: Genes that can bypass the CLN requirement for Saccharomyces cerevisiae cell cycle START. Mol Cell Biol 1994, 14:2041-2047

31. Costanzo M, Nishikawa JL, Tang X, Millman JS, Schub O, Breitkreuz K, Dewar D, Rupes I, Andrews B, Tyers M: CDK activity antagonizes Whi5, an inhibitor of G1/S transcription in yeast. Cell 2004, 117:899-913.

32. de Bruin RA, McDonald WH, Kalashnikova TI, Yates J 3rd, Wittenberg C: Cln3 activates G1-specific transcription via phosphorylation of the SBF bound repressor Whi5. Cell 2004, 117:887-898.

33. Nasmyth K, Dirick L: The role of SWI4 and SWI6 in the activity of G1 cyclins in yeast. Cell 1991, 66:995-1013.

34. Alberghina L, Smeraldi C, Ranzi BM, Porro D: Control by nutrients of growth and cell cycle progression in budding yeast, analyzed by double-tag flow cytometry. J Bacteriol 1998, 180:3864-3872.

35. Johnston GC, Ehrhardt CW, Lorincz A, Carter BL: Regulation of cell size in the yeast Saccharomyces cerevisiae. J Bacteriol 1979, 137:1-5.

36. Tyson CB, Lord PG, Wheals AE: Dependency of size of Saccharomyces cerevisiae cells on growth rate. J Bacterio/ 1979, 138:92-98.

37. Jorgensen P, Rupes I, Sharom JR, Schneper L, Broach JR, Tyers M: A dynamic transcriptional network communicates growth potential to ribosome synthesis and critical cell size. Genes Dev 2004, 18:2491-2505

38. Schneider BL, Zhang J, Markwardt J, Tokiwa G, Volpe T, Honey S, Futcher B: Growth rate and cell size modulate the synthesis of, and requirement for, G1-phase cyclins at start. Mol Cell Biol 2004, 24:10802-10813.

39. Hoose SA, Rawlings JA, Kelly MM, Leitch MC, Ababneh QO, Robles JP, Taylor D, Hoover EM, Hailu B, McEnery KA, et al: A systematic analysis of cell cycle regulators in yeast reveals that most factors act independently of cell size to control initiation of division. PLoS Genet 2012, 8:e1002590.

40. Bernstein, KA, et al: Ribosome biogenesis is sensed at the Start cell cycle checkpoint. Mol Biol Cell, 2007. 18(3): p. 953-64.

41. Tokiwa G, Tyers M, Volpe T, Futcher B: Inhibition of G1 cyclin activity by the Ras/cAMP pathway in yeast. Nature 1994, 371:342-345.

42. Flick K, Chapman-Shimshoni D, Stuart D, Guaderrama M, Wittenberg C Regulation of cell size by glucose is exerted via repression of the CLN1 promoter [published erratum appears in Mol Cell Biol 1998 Jul;18 (7):4407]. Mol Cell Biol 1998, 18:2492-2501.

43. Stuart D, Wittenberg C: CLN3, not positive feedback, determines the timing of CLN2 transcription in cycling cells. Genes Dev 1995, 9:2780-2794.

44. Polymenis M, Schmidt EV: Coupling of cell division to cell growth by translational control of the G1 cyclin CLN3 in yeast. Genes Dev 1997 11:2522-2531

45. Fontana $L$, Partridge $L$, Longo VD: Extending healthy life span-from yeast to humans. Science 2010, 328:321-326.

46. Schaefer JB, Breeden LL: RB from a bud's eye view. Cell 2004, 117:849-850.

47. Wang H, Carey LB, Cai Y, Wijnen H, Futcher B: Recruitment of Cln3 Cyclin to Promoters Controls Cell Cycle Entry via Histone Deacetylase and Other Targets. PLoS Biol 2009, 7:e1000189.

48. Cooper $\mathrm{K}: \mathrm{Rb}$, whi it's not just for metazoans anymore. Oncogene 2006, 25:5228-5232

49. Zhou P, Jiang W, Zhang YJ, Kahn SM, Schieren I, Santella RM, Weinstein IB: Antisense to cyclin D1 inhibits growth and reverses the transformed phenotype of human esophageal cancer cells. Oncogene 1995, 11:571-580

50. Quelle DE, Ashmun RA, Shurtleff SA, Kato JY, Bar-Sagi D, Roussel MF, Sherr CJ: Overexpression of mouse D-type cyclins accelerates G1 phase in rodent fibroblasts. Genes Dev 1993, 7:1559-1571.

51. Kerkhoff E, Ziff EB: Cyclin D2 and Ha-Ras transformed rat embryo fibroblasts exhibit a novel deregulation of cell size control and early $\mathrm{S}$ phase arrest in low serum. EMBO J 1995, 14:1892-1903.

52. Ohtsubo M, Roberts JM: Cyclin-dependent regulation of $\mathrm{G} 1$ in mammalian fibroblasts. Science 1993, 259:1908-1912.

53. Zacharek SJ, Xiong Y, Shumway SD: Negative regulation of TSC1-TSC2 by mammalian D-type cyclins. Cancer Res 2005, 65:11354-11360.

54. Classon M, Salama S, Gorka C, Mulloy R, Braun P, Harlow E: Combinatorial roles for pRB, p107, and p130 in E2F-mediated cell cycle control. Proc Natl Acad Sci U S A 2000, 97:10820-10825.

55. Herrera RE, Sah VP, Williams BO, Makela TP, Weinberg RA, Jacks T: Altered cell cycle kinetics, gene expression, and $\mathrm{G} 1$ restriction point regulation in Rb-deficient fibroblasts. Mol Cell Biol 1996, 16:2402-2407.

56. Fang SC, de los Reyes C, Umen JG: Cell size checkpoint control by the retinoblastoma tumor suppressor pathway. PLoS Genet 2006, 2:167.

57. Neufeld TP, de la Cruz AF, Johnston LA, Edgar BA: Coordination of growth and cell division in the Drosophila wing. Cell 1998, 93:1183-1193.

58. (http://www.yeastgenome.org/cache/genomeSnapshot.html) ScGS

59. Winzeler EA, Shoemaker DD, Astromoff A, Liang H, Anderson K, Andre B, Bangham R, Benito R, Boeke JD, Bussey $H$, et al: Functional characterization of the $\mathrm{S}$. cerevisiae genome by gene deletion and parallel analysis. Science 1999, 285:901-906.

60. Fisk DG, Ball CA, Dolinski K, Engel SR, Hong EL, Issel-Tarver L, Schwartz K, Sethuraman A, Botstein D, Cherry JM: Saccharomyces cerevisiae S288C genome annotation: a working hypothesis. Yeast 2006, 23:857-865.

61. Yang J, Dungrawala H, Hua H, Manukyan A, Abraham L, Lane W, Mead H, Wright J, Schneider BL: Cell size and growth rate are major determinants of replicative lifespan. Cell Cycle 2011, 10:144-155.

62. Nash RS, Volpe T, Futcher B: Isolation and characterization of WHI3, a sizecontrol gene of Saccharomyces cerevisiae. Genetics 2001, 157:1469-1480.

63. Manukyan A, Zhang J, Thippeswamy U, Yang J, Zavala N, Mudannayake MP, Asmussen M, Schneider C, Schneider BL: Ccr4 alters cell size in yeast by modulating the timing of CLN1 and CLN2 expression. Genetics 2008, 179:345-357.

64. Guo J, Bryan BA, Polymenis M: Nutrient-specific effects in the coordination of cell growth with cell division in continuous cultures of Saccharomyces cerevisiae. Arch Microbiol 2004, 182:326-330.

65. Planta RJ, Mager WH: The list of cytoplasmic ribosomal proteins of Saccharomyces cerevisiae. Yeast 1998, 14:471-477.

66. Krause-Buchholz U, Schobel K, Lauffer S, Rodel G: Saccharomyces cerevisiae translational activator Cbs1p is associated with translationally active mitochondrial ribosomes. Biol Chem 2005, 386:407-415

67. Rohde JR, Bastidas R, Puria R, Cardenas ME: Nutritional control via Tor signaling in Saccharomyces cerevisiae. Curr Opin Microbiol 2008, 11:153-160.

68. Fingar DC, Salama S, Tsou C, Harlow E, Blenis J: Mammalian cell size is controlled by mTOR and its downstream targets S6K1 and 4EBP1/elF4E. Genes Dev 2002, 16:1472-1487. 
69. Zhang H, Stallock JP, Ng JC, Reinhard C, Neufeld TP: Regulation of cellular growth by the Drosophila target of rapamycin dTOR. Genes Dev 2000, 14:2712-2724.

70. Kikuchi Y, Mizuuchi E, Nogami S, Morishita S, Ohya Y: Involvement of Rhotype GTPase in control of cell size in Saccharomyces cerevisiae. FEMS Yeast Res 2007, 7:569-578.

71. Koch C, Wollmann P, Dahl M, Lottspeich F: A role for Ctr9p and Paf1p in the regulation G1 cyclin expression in yeast. Nucleic Acids Res 1999, 27:2126-2134.

72. Lussier M, White AM, Sheraton J, di Paolo T, Treadwell J, Southard SB, Horenstein Cl, Chen-Weiner J, Ram AF, Kapteyn JC, et al: Large scale identification of genes involved in cell surface biosynthesis and architecture in Saccharomyces cerevisiae. Genetics 1997, 147:435-450.

73. Dirick L, Bohm T, Nasmyth K: Roles and regulation of Cln-Cdc28 kinases at the start of the cell cycle of Saccharomyces cerevisiae. EMBO J 1995, 14:4803-4813.

74. Cross FR: Starting the cell cycle: what's the point? Curr Opin Cell Biol 1995, 7:790-797.

75. Futcher B: Cyclins and the wiring of the yeast cell cycle. Yeast 1996, 12:1635-1646

76. Dirick L, Nasmyth K: Positive feedback in the activation of G1 cyclins in yeast. Nature 1991, 351:754-757.

77. Radcliffe P, Trevethick J, Tyers M, Sudbery P: Deregulation of CLN1 and CLN2 in the Saccharomyces cerevisiae whi2 mutant. Yeast 1997, 13:707-715

78. Ogas J, Andrews BJ, Herskowitz I: Transcriptional activation of CLN1, CLN2, and a putative new G1 cyclin (HCS26) by SWI4, a positive regulator of G1-specific transcription. Cell 1991, 66:1015-1026.

79. Cvrckova F, Nasmyth K: Yeast G1 cyclins CLN1 and CLN2 and a GAP-like protein have a role in bud formation. EMBO J 1993, 12:5277-5286.

80. Bloom J, Cross FR: Multiple levels of cyclin specificity in cell-cycle control. Nat Rev Mol Cell Biol 2007, 8:149-160.

81. Niu W, Li Z, Zhan W, lyer VR, Marcotte EM: Mechanisms of cell cycle control revealed by a systematic and quantitative overexpression screen in S. cerevisiae. PLoS Genet 2008, 4:e1000120.

82. Schneider BL, Patton EE, Lanker S, Mendenhall MD, Wittenberg C, Futcher B, Tyers M: Yeast G1 cyclins are unstable in G1 phase. Nature 1998, 395:86-89.

83. Tyers $M$, Futcher B: Far1 and Fus 3 link the mating pheromone signal transduction pathway to three G1-phase Cdc28 kinase complexes [published erratum appears in Mol Cell Biol 1994 Mar;14(3):2222]. Mol Cell Biol 1993, 13:5659-5669.

84. Kaeberlein M, Powers RW 3rd, Steffen KK, Westman EA, Hu D, Dang N, Kerr EO, Kirkland KT, Fields S, Kennedy BK: Regulation of yeast replicative life span by TOR and Sch9 in response to nutrients. Science 2005, 310:1193-1196.

85. Steffen KK, McCormick MA, Pham KM, Mackay VL, Delaney JR, Murakami CJ, Kaeberlein M, Kennedy BK: Ribosome Deficiency Protects Against ER Stress in Saccharomyces cerevisiae. Genetics 2012, .

86. Ausubel FM: Current protocols in molecular biology. Brooklyn, N. Y: Media, Pa. Greene Publishing Associates; 1987.

\section{Submit your next manuscript to BioMed Central and take full advantage of:}

- Convenient online submission

- Thorough peer review

- No space constraints or color figure charges

- Immediate publication on acceptance

- Inclusion in PubMed, CAS, Scopus and Google Scholar

- Research which is freely available for redistribution 